\title{
COMMENTARY
}

\section{OPEN ACCESS - PANACEA OR PANDORA'S BOX?}

\author{
Andrew Kerr \\ Department of Earth Sciences \\ Memorial University \\ St. John's, Nenfoundland and Labrador, A1B 3X5, CANADA \\ E-mail:akerr@mun.ca
}

The publishing industry has altered beyond all recognition in the first two decades of the $21^{\text {st }}$ century, and scientific journals cannot evade the ever-shifting winds of change. There has been a fundamental leap from the expensive hardcopy printing of glossy scientific journals to online digital delivery of most content. Even for those journals that maintain print format, production is less, and many scientists now elect to do their reading and research from a laptop or a tablet. Geoscience Canada went 'digital only' about four years ago, and the advantages in terms of costs and flexibility are clear. I will admit that I personally miss the feeling of relaxing in a comfortable chair with my coffee and flipping through the printed pages, but there is no going back on this trend. Online publishing transforms access to scientific material on a global basis; readers on the other side of the world, where libraries would likely not archive printed copies of Geoscience Canada, can now easily read our scientific papers. Providing, that is, that they buy a personal subscription, or that their employer or institution (if they have one) holds an institutional subscription. Our annual subscription fee is amazing value (at less than $\$ 100$ per year), but costs for some geoscience journals are hundreds or even thousands of dollars annually, and institutional subscriptions are even more expensive. Online publishing still requires subscriptions, because it depends on users paying for access, but such access does not come cheap. This seems a strange paradox, given the cost of digital publishing is so much less than printed media. Many universities now face severe challenges in maintaining these expenditures, and subscriptions to specialized journals are being discontinued, leading to protests from individual researchers.

However, those in the ivory towers remain the most favoured in terms of their access to online journals. Ironically, the online digital revolution has actually made access to this vital information more difficult for others within the research community. Those who work outside universities or select government institutions have more limited access, and it is becoming increasingly difficult to seek out such material at your local university library, if indeed one is available to you. Procuring a copy of some hard-to-find article can be a real challenge, and the cost of downloading a single paper is as much as buying a hardcopy book - in some cases the only recourse is to beg the assistance of academic colleagues or even students. Gone are the days when I would walk down Elizabeth Avenue on a nice day to browse some recent issues of journals in the periodicals reading room at Memorial University. Most of the journals that I used to look for are no longer even on the shelves, and hardcopy back issues are increasingly relocated to distant, dusty and inconvenient offsite storage. Papers that are published by scientists who are supported by government funding, in government institutions and at universities, now often appear in journals that the general public or unaffiliated researchers cannot freely or easily access. The online digital revolution makes the sharing of information easier for all of us, and the internet now connects us across the globe, but this new tree of knowledge has yet to fully blossom for scientific publishing. This again seems paradoxical, for commercial scientific publishing remains highly profitable even in times when most other parts of the sector confront serious fiscal challenges in maintaining their business models. Even before low-cost online publishing arrived, scientific publishers enjoyed lower costs, because the authors of papers are unpaid, as are the reviewers and most scientific editors. Given this backdrop, it is not surprising that discontent with access restrictions and increasing subscription costs has grown, and some in the research community have called for deliberate boycotts of prominent corporate publishers. It is also not surprising that research funding agencies, which mostly disperse public resources, are increasingly concerned that their investments are not rewarded by wide visibility and availability of their research.

The Open Access concept emerged as a possible solution to this growing dilemma, and it is now a persistent topic wherever scientists gather and talk, although opinions and viewpoints are understandably diverse. Three research funding agencies in Canada, including NSERC, which is the principal source for geoscience research funding, now require that peer-reviewed 
publications be made freely available to all within one year of their initial publication. Essentially, grant recipients must facilitate open access to the results of research funded by the public through NSERC. Broadly similar policies exist, or soon will exist, in most other western countries, including the United States and much of the European Union. Open access is a new reality that researchers and scientific journals must now address, but we do not yet fully understand the long-term implications of this latest paradigm shift. Nevertheless, I feel confident in predicting that open access will bring more irreversible changes in scientific publishing, and that it may also affect how Geoscience Canada functions in the future.

We are in many respects already an open access journal, because all of our content is available without subscription about two years after publication. Everyone agrees that complete 'open access' to the results of research benefits all of us in the long run, but there is little or no consensus about how this can be achieved on a sound fiscal basis. The costs of publishing online are indeed reduced, and many of us who participate in the process remain essentially unpaid, but the production of complex papers still requires money as much as it does time, dedication and effort. These financial resources presently come from subscriptions, and in the case of non-profit society journals such as Geoscience Canada, partly from other sources such as operating grants. For a journal to publish high-quality, peer-reviewed research on a long-term sustainable basis, it must have some reliable sources of revenue. For commercial publishers, these operations must also provide profits to the parent company and its shareholders. Geoscience Canada, like other society journals, redirects any profits into expanding publication activities, but we still have the need for long-term fiscal sustainability. If the money runs out, publishing the papers will be curtailed.

Open access is a complicated and controversial topic, and a short piece such as this cannot address all possible ramifications. A very good source for those interested in details and debates is an article published three years ago in Elements (Speer et al. 2013). There are presently two main 'flavours' of open access, which are referred to as Gold and Green. In the Gold Model, immediate unrestricted access is provided to the final published article on the publisher's website, following payment of an Article Processing Charge (APC) by the author(s) or their institution(s). In the Green Model, access to the final published paper on the publisher's website remains behind a subscription wall, but the author(s) are permitted to place an equivalent document (typically, the accepted manuscript) in an online data repository, or on a personal or institutional website. Clearly, the Gold Model has multiple advantages in terms of easily locating and accessing material, but is more costly to authors; the policies relating to the Green Model vary widely but some commercial publishers still do not permit authors to make their work available in any alternate fashion. The Gold Model spawned the interesting concept of Open Access Journals, which are funded almost entirely through APC payments - such journals support themselves (or generate profits) through a model that is in some respects reminiscent of the self-publishing industry. However, to be fair, it is not the same as prospective novelists quickly publishing their own unedited work, because some open access journals subject submissions to peer-review, and there is no guarantee of acceptance for any given manuscript. Nevertheless, there are growing concerns about the integrity of the peer-review process in circumstances where the rapid acceptance and publication of papers brings direct financial benefit. The open access journals generally also have lower 'impact factors' than established traditional journals, so they are not widely favoured by authors. Open access policies currently developed by Canadian agencies recognize APC payments as an eligible use of research funding, but not all authors have access to such funding, and their institutions or employers may not be willing to cover such costs. Open access journals operating on this funding strategy would thus not be available to all researchers or writers, and if they become the norm, their terms could suppress valuable work and thought by authors who lack financial resources. There is, however, a compromise between the status quo and fully open-access journals. Some scientific journals make open access possible through a more flexible policy where immediate access to papers is facilitated through an optional payment, following final acceptance of a paper for publication. Many recommend this hybrid model as the most prudent approach for society-managed, non-profit journals, and it forms the basis for the open access initiative that Geoscience Canada is introducing as of volume 43 . We will become a bybrid journal, in which some content (such as this piece) is freely available, but other scientific articles will still require subscription access, unless the authors and/or their institutions have opted for open access. We term these optional charges Open Access Supplements (OAS) as they are not strictly related to processing of the articles.

I must here reiterate a very important point - Geoscience Canada is already an open access journal in many respects. The material that we have published over 40 years is for the most part freely available to all through our archives, as our modest annual subscriptions apply only to the current volume and the two previous years. In this respect, we differ from many other society-funded journals, in which all previous content remains behind a subscription wall. We are already a long way down the open access road, and we are very proud of this attribute. If you have an article in our editorial pipeline, or plan to soon submit a manuscript, you do not yet need to think about open access, in fact, we prefer not to discuss it prior to acceptance of a final revised manuscript. Our assessment of manuscripts and the comments and suggestions made by peer reviewers will remain impartial and uninfluenced by the prospect of OAS revenue. This is the core ethos of all scientific publishing: there must be no possibility of a bad paper being accepted simply because it will provide revenue. The integrity of our peer-review and assessment process will be faithfully respected. When a revised manuscript is finally accepted, the author(s) will be presented with options for gaining open access. The OAS is scaled to the length of the paper, and consists of a flatrate charge of $\$ 1000$, plus $\$ 100$ per printed journal page; thus, a ten-page scientific paper will incur an OAS of $\$ 2000$. We also offer a second option that provides open access one year from the publication date for a lesser rate of $\$ 500$ plus $\$ 50$ per published page. This latter option will satisfy policies now announced for research funding agencies in Canada. Decisions on open access do not have to be made upon acceptance of a paper; the OAS can be paid at a later time, after which the controls on access to the article will be removed. 
These new open access policies are entirely optional; there is no requirement that an OAS be paid if authors or their institutions are content that access to the article will require a Geoscience Canada subscription for the first two years. Submission of an article, or its acceptance, will impose no obligation on authors to eventually provide OAS payments. The fee structure proposed for Geoscience Canada compares very favourably to those now in place for some other geoscience journals, and articles that are not open access upon publication will continue to become freely available after two years from issue publication.

Some of you will undoubtedly be asking why Geoscience Canada is making this choice, or why we even need to consider imposing charges for open access. You might also wonder if we plan to eventually become a fully open access journal. Funding agencies require that access to research become as wide and easily accessible as possible, and we have to respond to this reality. We have done so by implementing a reasonable and optional process that will allow us to continue publishing quality science, while meeting the journal's financial obligations. We cannot predict how many authors will ultimately opt for open access, but it is clear that should a large portion of our technical content become unrestricted, the incentives for personal and/or institutional subscriptions will diminish, and we will inevitably lose subscription revenue. Resources are needed to continue publishing because our long term goal goes beyond maintaining the status quo - we want to expand, diversify and increase our impact. Geoscientists should be very familiar with the necessity of change because the fossil record clearly demonstrates the fate of those who fail to adapt when environments shift. Some pundits have even suggested that the effects of open access on traditional scientific publishing could resemble a mass extinction. Should that be the case, Geoscience Canada has every intention of being amongst the survivors. It is not presently in our plans to become an open access journal funded entirely by OAS revenue, but if our strategy catches on with authors, it may be possible for us to eventually provide open access to more authors who lack the ability to meet OAS charges. We cannot predict where this road will lead us, but instead must just follow it and find out.

I will close with some thoughts that reveal my own advancing age. When I started submitting manuscripts over 30 years ago, the concept of page charges was common, and these still exist for some print-based journals. Upon acceptance of a paper, a request for settlement of page charges was made to authors, but final publication was not dependent upon payment. Page charges instead supported the operations and costs of the journal, and employers and institutions were generally agreeable to their payment. As a proud new author, I used to buy packages of glossy reprints for each article, and send them out to my colleagues and collaborators, or in response to 'reprint requests' that arrived on neat little cards in the mail. The sale of reprints to authors also helped journals meet their costs. Even today, some journals levy significant charges for 'clean' PDF-format files without watermarks that authors are allowed to send to colleagues, but Geoscience Canada will continue to give these to authors for free. At Geoscience Canada, we are fully aware that we are about to navigate some uncharted waters, and some might feel that our planned route is unwise. If you soon receive one of those welcome letters that con- firms acceptance of your paper, but then suggests that you or your institution might wish to part with a few thousand dollars, just think back to those vanished days of page charges. Open access is really not so different in its overall concept. But then remember that open access, should you choose to pay for it, gives you something that page charges never could. It guarantees that the entire world has immediate access to the hardwon results of your scientific endeavours with the click of a mouse. I think you will agree that such impact has considerable value.

\section{SOME USEFUL REFERENCES AND SOURCES}

Cheung, M., 2015, Open Access, Open Data, Open Science: Canadian Science Publishing; blog entry. Available at www.cdnsciencepub.com. Open Access.

Government of Canada, 2015, Tri-Agency Open Access Policy on Publications. Available at www.science.gc.ca. Open Access.

Kettley, S., 2015, The business of open access: collaborating on a way forward: Canadian Science Policy Centre. Available at www.sciencepolicy.ca/news. Open Access.

Lariviere, V., Haustein, S., and Mongeon, P., 2015, The oligopoly of academic publishers in the digital era: PLOS ONE, June 2015, http://dx.doi.org/10.1371/ journal.pone.0127502 (PLOS ONE is a non-profit open access multidisciplinary journal). Open Access.

Speer, A. J., Murphy, K., and Tahirkheli, S., 2013, Open Access: A Current Perspective: Elements, v. 9, p. 85 - 87. Available at http://www.elementsmagazine.org/ archives/e9_2/e9_2_dep_perspective.pdf. Open Access. 